\title{
Political System Legitimation in Network Society
}

\author{
Olga D. Shipunova ${ }^{1}$, Igor E. Timermanis ${ }^{1} \&$ Lidiya I. Evseeva $^{1}$ \\ ${ }^{1}$ Humanitarian Institute, St. Petersburg State Polytechnical University, St. Petersburg, Russian Federation \\ Correspondence: Olga D. Shipunova, 29-1-116, pr. Aviakonstruktorov, St. Petersburg, 197373, Russian \\ Federation. Tel: 7-891-119-45042.
}

Received: August 21, 2014 Accepted: September 22, 2014 Online Published: November 13, 2014

doi:10.5539/res.v6n4p69

URL: http://dx.doi.org/10.5539/res.v6n4p69

\begin{abstract}
The article analyzes the range of information and communicative resources for maintaining political system stability. Electronic media efficiency is examined from the point of social control in public sphere. Person's social adaptation in terms of globalization and informational pressure from media structures appears to be rather complex process, so political system legitimating on the basis of recognition and trust to the power acquires its problematical character. The need of searching for any new forms of streamlining of both information and communicative space serving the political system, results from the principles of socio-cognitive approach. Any information, whether directed or non-directed, in communication network acts as the prerequisite for each person's action; this makes information a capacious resource for political system stabilization, though ambiguous owing to distinctions in value mindsets and arising semantic barriers in personal processes of transferred message assessment.
\end{abstract}

Keywords: political system, information and communication network, public sphere, social control, deliberative policy

\section{Introduction}

The question about how communication methods in use influence on the political component of state and social development, gains specific relevance in the conditions of prompt development of information and communication technologies (Naisbitt, 1990). In particular, in the second half of the $\mathrm{XX}^{\text {th }}$ century television already acts as an effective channel for mass socio-political influence translation (McLuhan, 1967). Nowadays one can note that electronic technologies become a means of social communications maintenance. In the modern world, network structures, which are both means and product of modern society globalization, constitute new social morphology. Network relations penetrate political system insomuch that they start being considered as the main instrument for citizen's identification, organization and coordination of political participation of elite and non-elite social strata (Solovyov, 2002, p. 7). Presence of network logic considerably affects progress and result of the processes connected with production, everyday life, culture and power (Castells, 1999; Bodrunova, 2013; Tarakanova, 2012). In this regard, complex analysis of information and communicative interactions aimed to ensure political system legitimacy and stability becomes a priority task of social management theory and practice.

\subsection{Literature Review}

A.Toffler emphasized the increase of mass media interactivity due to new network technologies introduction, and believed that by the XXIst century outcome information and knowledge would have become the most important resources of power (Toffler, 1980). As communications are the vital part of human existence, any changes in communication methods have substantial effects for power distribution in society-because of social values revision inevitably leading to changes in citizens' individual and political consciousness (Deibert, 1997).

In Deutsch's theory (Deutsch, 1963), political system appears as a complex network of information streams and communicative relations, constructed on the feedback principle. Efficiency of political system functioning depends on its communication networks condition, arriving information quantity and quality, specific features of chained messages processing, transfer and storage.

As to M.Castells, modern information and communication technologies constitute one of the most significant factors of political system transformation which is accompanied by formation of electronic media structures of the power. While characterizing the signs of oncoming world order, Castells notes a contradiction between global 
activity of multinational corporations and locality of taxation that deprives a national state of space for maneuver and real control levers. At the same time, importance of civil society institutes and organizations in people life, which lose the "legitimate identity", falls to more and more extent (Castells, 2000-2004, p. 27).

Activity of modern mass media as the most important agents of information space, as approved by P.Norris, generates three basic effects providing direct correlation with level of civil consciousness of population. "The effect of choice" indicates potential possibility of free choice of information source. "The media effect" indicates people's interest in political and civil participation which is caused by news policy of mass media. "The interaction effect" is expressed in interactivity of mass information system and emergence of steady dependence between obtaining information and forming of political civic position (Norris, 2000).

D. Wolton shows that Internet as communicative means provokes surge in individualism and sharp strengthening of inequality. Besides, fast transfer of huge array of information is certainly not equivalent to improvement of communication quality. Internet in a sense "loses" to radio and television which in much bigger degree promote establishment and strengthening of social relations, providing easy and equal access to information and creating wide opportunities for impact on public opinion (Wolton, 2000). J.Dufresne reckons all of such phenomena as reduction of real communication between people, a gap between individual abilities and need to learn and process huge volumes of information, intellectual passivity and superficiality, universal currency of "social virtuality", when idea of reality becomes much more important than the reality itself, into the range of negative results of Internet development (Dufresne, 1999).

Society only seems to be the static sum of social institutes. Actually, it revives day by day or is creatively reproduced by means of certain communicative acts taking place between its members (Tiggun, 2007, p. 67). Marking out key value of interactive dynamics in public sphere, J.Habermas emphasizes disclosure, openness, effectiveness of public opinion. According to Habermas, discourse is the most effective form of communicative action expression in network society (Habermas, 1983, pp. 91-92).

The problem of political system legitimating on the basis of national acknowledgement and trust to power is defined by the fact that in interactions, political discourse isn't a precise mechanism of social influence broadcasting direct motivation to action. Communication as social practice constitutes the most important problem of deliberative policy (Boniolo, 2012). Commitment to democratic principles, which is popular in modern world, stimulates social interest to the semantic context of social interactions based on value and archetype mechanisms. The priority of semantic principle in regulation of conscious and unconscious dynamics of personality's inner world is discovered in socio-cognitive approach (Dijk, 2008) by the idea of contextual model which, on the one hand, acts as discourse, and on the other, presents a kind of subjective mental model.

\section{Materials and Methods}

Panorama of communication revolution in the literature can be analyzed in three directions: information operating - virtual reality—social interaction (Tikhonova, 2007).

Informational exchange forms basic prerequisites for steady political system formation which is characterized by three main types of communication: 1) personal, informal communications; 2) communications via organizations; 3) communications through mass media. Overall objective of political communication is an interaction between policy subjects by means of informational exchange during the processes of race for power, its exercise or retention. This purpose is realized by focused transfer and selective reception of information.

Nowadays, global infrastructure of electronic means of information collecting, storage, processing and transfer impresses with the scale of its influence on socio-political relations system. The first (latent) wave of information (from the end of XIXth century to the fifties of the XXth century) only slided over the political life of society. The second wave actually created new social reality (Boom in large-size, 1988) which demands absolutely new types of organization, behavior, motivation and ethics. Huge mass of people needs behavior samples providing their quick adaptation for new forms of public life. Obtaining information is perceived by mass consciousness as the only and reliable way to success, as the mechanism of public regulation.

Information and communication network of political system, according to Deutsch, includes: services of information reception, information assessment and selection, decision-making, decisions implementation, and feedback (Deutsch, 1963). At the first stage, external and internal information is gathered via information services and centers of public opinion formation; this information doesn't rigidly correlate to subsequently formulated purposes of state policy. At this block, selection, systematization, primary analysis and coding of arriving data is made. After its assessment and processing, selected information inputs the "memory and values" block, where it is exposed to additional transformation according to dominating values, norms, stereotypes, 
preferences of ruling elite.

The government as the subject of public administration mobilizes political system by information streams regulation and communication interactions between system and social environment, and between separate blocks within the system. Governmental decisions are made after receiving a total assessment of current political situation compliance to the main objectives and purposes of state policy. Feedback in information and communication network plays stabilizing role. "Effectors" not only implement decisions made, but also inform on results of decisions' implementation and on the whole system condition. Thus, new information via the feedback mechanism gets on "input" again and brings all the system to a new round of functioning.

Communication network of political system broadcasts three main types of messages: a) technological data concerning contact establishment and maintenance between the elements of political system; b) informative data conveying main semantic meaning of transferred message; c) incentive appeals causing desire or understanding in need of some actions according to the contents of received information. Possibility of success in social management 1) is inversely proportional to information loading and delay of system reaction; 2) depends on an increment of system reaction to changes; 3 ) depends on ability of power structures to see prospects and to take necessary actions in case of threats for political stability (Deutsch,1969, p. 13).

Deutsch's information and communication model provides estimation of political systems efficiency. But within this approach the problem of interaction efficiency between communicator and recipient is reduced to only studying of various channels, ways and methods for information transfer, thus leaving processes of individuals' perception and reciprocal behavior actually out of sight.

Information network assumes not only subjects depersonalization, but also ability of citizens to choose necessary information. Energy of mass, active and politically functioning public sphere shouldn't be ignored neither in information and communicative space of virtual reality nor in real historical space and time.

Influence on personal civic and political position deals with complex interlacing of consciously perceived information, unconscious motives, factors of spontaneous influence (such as individual life experience, living conditions, cultural and social environment). Public shouldn't be considered as a passive object of political influence. It treats selectively all types of external influence, accepting and acquiring ones and rejecting others. Objectively good information stuff can appear to be practically much less effective than communicators and owners of mass information system would expect. Public would simply not perceive information or perceive it in a wrong way. As a result, the material, instead of forming belief, will serve to excess amplifying of available views, relations, and mindsets inducing to actions.

Network communications are characterized with decentralization, flexibility, mobility, variability of forms and configurations; ease and speed of structures creation and disintegration; openness, general availability of network resources; equality of network participants. In the world of network structures, along with states, global "networks" and individuals, there are communities which are united with "identity of resistance". For such communities, protest moods and minimum inclusiveness into traditional civil structures are characteristic. In prospect, some of them, after having overcome identity of resistance, will be able to proceed to "identity directed in the future". It will allow them to create new civil society and new state. This specific potential presents in female, ecological, religious, national and territorial associations, especially taking into account that increasing of universal activity of territorial originality would conduct to returning of "city-states" on the historical scene (Materials for an Exploratory Theory of Network Society, 2000, pp. 5-14).

\section{Results}

Informational pressure from media structures and political discourse ambiguity contributing emotional attitudes, evaluations and meanings broadcasting process result into uncontrolled and spontaneous character of political system legitimating, due to implicit dynamics of human consciousness and inadequate of informational perception.

Political discourse enters a rating scale, but assumes latent reference to norms and values. Nevertheless, it is an idea of reference to value in individual sub consciousness lying in the basis of internal and indirect social control of public sphere in community self-organization. In this case, personal vital world invariants naturally (intuitively) correspond to discourse as an imperative communicative condition of understanding during interactions, thus forming motivational complex.

Movement towards deliberative democracy requires a seamless combination of individual freedom and, at the same time, political directive to the total control of public sphere. Presence of these quite opposite motivation vectors makes total control of public sphere an unattainable ideal. Personification of meanings and values during 
the process of personal self-determination in political situation thus remains an opaque "black box" even in the conditions of full information openness in network society.

\section{Discussion}

Deliberative policy establishment in public sphere actualizes the problem of resources for individual actions and thoughts social control, which is carried out through individual's following certain inter-subjective norms. As Habermas notes, the norm is compulsory imperative; however, norm's claim to its general validity is problematic. Even in terms of moral argumentation imperative ethics misses any deeper value measurement of power justification (Habermas, 2010, pp. 172-175).

The value category, on the one hand, indicates a clear boundary of subjectivity and inter-subjectivity in social practice, on the other, provides this border elimination in existential processes of self-determination. The need for self-identification is underlain by combination of psychosocial (archetypes) and socio-cultural (values) factors into certain norm of communication, which is as a rule consecrated with tradition and implanted into discursive practice of communication and social behavior (Shipunova, 2014). Declaration of free and impartial discussion of values would face a communicative problem. As values have historically caused context, so any interaction requires continuous specification of value discourse.

While postulating regulatory requirements for language communication between equal partners and constituting conceptual basis of deliberative policy (Nazarchuk, 2011), discursive ethics doesn't solve, but just exacerbates the issue of basic value orientations discrepancy. In different cultures, regulatory requirements even for trueness appear to be ambiguous.

Communicative processes are forming and formatting the cultural and political space. In this case, power and influence become belonging to those who is capable to create new cultural codes necessary for social subject (both community as a whole and every individual) during the processes of adequate reality reflection and development of conscious decisions (Castells, 2000-2004; Gorbatova \& Stankevitch, 2001; Gura \& other, 2010). While keeping its influence, political system in a certain sense has no power, as it appears, in both traditional and information society, to be entered into cultural codes which people and institutes use to organize their lives and make decisions, including political ones.

\section{Conclusion}

Purposeful contacts between people possessing various knowledge, data, messages, connect different levels of political system and give institutes of power an opportunity to carry out the specific functions on social management. In this context, information acts as both prerequisite for any political subject action and its major resource providing effective interaction in political sphere for the sake of purpose achievement.

The informational revolution happening in the modern world is accompanied by communication penetration into all spheres of activity, causing global social and political transformations. Today, one can distinctly feel sharp strengthening of communication network importance in political sphere. Implicit political influence on personal consciousness and person's civic and political position formation is carried out in a network format declaring freedom of choice.

New information technologies change quality and structure of the political market offer, promoting large increase of interactive relations density between elite and non-elite social strata.

In modern society, one can't ignore informal plebiscitary mechanisms arising on the basis of new network relations and being induced with the values' transformation caused by opposite processes of globalization and glocalization. In this regard, an idea of social order becomes problematic. Reflection of social order bases, implicit mechanisms of social self-organization, in particular social coding, meanings and values personification, mental and cultural structures interrelations in terms of historical and interactive social dynamics-all these phenomena come to the forefront of actual analysis of political system stability conditions.

\section{Acknowledgement}

The authors acknowledge receiving support from Institute of humanitarian education of National Research University St. Petersburg State Polytechnical University for the years 2013, 2014. We are responsible for all errors as well as heavy style of the manuscript.

\section{References}

Bodrunova, S. S. (2013). State image as a criterion of applied assessment of the state's political conditionality. Humanities and Social Sciences, 4(184), 38-42. 
Boniolo, G. (2012). The Art of Deliberating: Democracy, Deliberation and the Life Sciences between History and Theory. In Studies in Applied Philosophy, Epistemology and Rational Ethics (Toм 6) (p. 204). Springer Science \& Business Media. http://dx.doi.org/10.1007/978-3-642-31954-9

Castells, M. (1998). The Information Age. Economy, Society and Culture. Oxford, Malden, MA: Blackwell.

Castells, M. (1999). The Power of Identity, the Information Age: Economy, Society and Culture (Vol. 2). Moscow, Russia.

Deibert, R. J. (1997). Parchment, Printing, and Hypermedia: Communications in World Order 3. New York: Columbia University Press.

Deutsch K. (1969). Politische Kybernetik: Modelle und Perspektiven. Freiburg.

Deutsch, K. (1963). The Nerves of Government Modesl of Political Communication and Control. New York.

Dijk van, T. A. (2008). Discourse and context. A sociocognitive approach (p. 288). Cambridge University Press, NY. http://dx.doi.org/10.1017/CBO9780511481499.005

Gorbatova, N. V., \& Stankevitch, L. T. (2001). Informational technologies. Virtual myths and political reality in Russia. In Humanitarian technologies and political process in Russia. Saint-Petersburg, Russia.

Gura, V. A., Safonova, A. S., \& Shipunova, O. D. (2010). Codes of truth in history of culture. Culturology Issues, 6, 53-58.

Habermas, J. (1983). Moralbewußtsein und kommunikatives Handeln. Frankfurt am Main.

Habermas, J. (2010). Problem of late capitalism legitimization (p. 264). M.: Praksis.

McLuhan, M. (1967). The Timid Giant. In Understanding Media: the Extensions of Man (pp. 329-343). Sphere Books Limited London, England.

Nazarchuk A. V. (2011). The Concept of Deliberative Policy in Modern Political Process. POLIS, 5, 99-103.

Norris, P. A. (2000). Virtuous Circle, Political Communication in Postindustril Societies (p. 420). NY: Cambridge University Press. http://dx.doi.org/10.1017/CBO9780511609343

Shipunova, O. D. (2014). The Role of Relation to Values Principle in the Social Management Practices. The Existential-Communicatory Aspect. Middle-East Journal of Scientific Research, 19(4), 565-569.

Solovyov, A. I. (2002). Communication and Culture: Contradictions of the Field of Politics. POLIS, 6.

Tarakanova, T. S. (2012). Features of information and communication technologies in deliberative democracy concept. St. Petersburg State Polytechnical University Journal, 1(141), 28-32.

Tikhonova, S. V. (2007). Communication Revolution Today: Information and Network. POLIS, 3.

\section{Copyrights}

Copyright for this article is retained by the author(s), with first publication rights granted to the journal.

This is an open-access article distributed under the terms and conditions of the Creative Commons Attribution license (http://creativecommons.org/licenses/by/3.0/). 